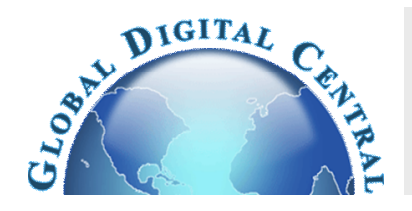

\author{
Frontiers in Heat and Mass Transfer \\ Available at www.ThermalFluidsCentral.org
}

\title{
HEAT TRANSFER ON MHD NANOFLUID FLOW OVER A SEMI INFINITE FLAT PLATE EMBEDDED IN A POROUS MEDIUM WITH RADIATION ABSORPTION, HEAT SOURCE AND DIFFUSION THERMO EFFECT
}

\author{
N. Vedavathi ${ }^{\mathrm{a}}$, G. Dharmaiah ${ }^{\mathrm{b} *}$, K.S. Balamurugan ${ }^{\mathrm{c}}$ and J. Prakash ${ }^{\mathrm{d}}$ \\ ${ }^{a}$ Department of Mathematics, Koneru Lakshmaiah Education Foundation, Vaddeswaram, Guntur, Andhra Pradesh, 522502, India. \\ ${ }^{b}$ Department of Mathematics, Narasaraopeta Engineering College, Yellamanda, Narsaraopet, Andhra Pradesh, 522601, India. \\ ${ }^{c}$ Department of Mathematics, RVR \& JC College of Engineering, Chowdavaram, Guntur, Andhra Pradesh, 522019, India. \\ ${ }^{d}$ Department of Mathematics, University of Botswana, 4775 Notwane Gaborone, PrivateBag, UB0022, Botswana.
}

\begin{abstract}
The effects of radiation absorption, first order chemical reaction and diffusion thermo on MHD free convective heat and mass transfer flow of a nanofluid past a semi infinite vertical flat plate are analyzed. The temperature and concentration at the surface are assumed to be oscillatory type. Four types of cubic nano particles which are uniform and size namely, Silver $(\mathrm{Ag})$, Aluminum $\left(\mathrm{Al}_{2} \mathrm{O}_{3}\right)$, $\mathrm{Copper}(\mathrm{Cu})$ and Titanium Oxide $\left.(\mathrm{TiO})_{2}\right)$ with water as a base fluid is taken into account. The set of ordinary differential equations are solved by using regular perturbation technique. The impact of various flow parameters on nanofluid velocity, temperature, concentration as well as the friction factor coefficient, the rate of heat and mass transfer coefficients are derived and discussed through graphs and tables.
\end{abstract}

Keywords: Nanofluids, Boundary layer flow, Radiation Absorption, MHD, Heat and Mass Transfer.

\section{INTRODUCTION}

Convective boundary layer flow, heat and mass transfer are influenced by nanofluid over a flat plate with diffusion thermo. It has tremendous applications in numerous areas like as glass blowing and elastic sheets. Nanofluid is a sort of heat and mass transfer fluids that contains base fluid and nano particles. Nanofluids utilized as a part of nanofluids are normally formed metals $(\mathrm{Al}, \mathrm{Cu})$, Oxides $\left(\mathrm{Al}_{2} \mathrm{O}_{3}, \mathrm{TiO}_{2}\right)$, nitriles ( $\mathrm{AlN}$, $\mathrm{SiN}$ ) and carbides $(\mathrm{SiC})$. Base fluid is typically a conductive liquid; for instant $\mathrm{C}_{2} \mathrm{H}_{6} \mathrm{O}_{2}, \mathrm{H}_{2} \mathrm{O}$ and engine oil. Nanofluids with or without the presence of magnetic field have numerous applications in the industries since materials of nanometer size have unique chemical and physical properties with regard to sundry utilizations of nano fluids, the cooling applications of nanofluids incorporate silicon mirror cooling, electronics cooling, vehicle cooling, transformer cooling and so on. Magneto-hydrodynamic convective flow issues are exceptionally imperitive and some of the works on chemical engineering, planetary and stellar magnetospheres and aeronautics can be found in (Ellahi (2013), Ali (2010), Noghehabadi et al. (2013), Mahabood et al. (2015)).

Nanofluids have been appeared to increase the thermal conductivity and convective heat transfer performance of the base liquids. Due to the increasing importance of nanofluids, there is a huge amount of literature on convective heat transport in nanofluids problems. Nanofluid is described as a fluid containing nanometer-sized particles, called nanoparticles within the length scale of 1-100 nm diameter and 5\% volume fraction of nanoparticles. These fluids are suspended in designing colloidal system of nanoparticles in a base fluid.

The hypothesis of nanofluid is first presented by Choi (1995) and has been a field of dynamic research area for about two decades. Choi has proposed the infusion of nano-size particles into regular fluids, for example, water and oil. He has demonstrated experimentally that the injection of these particles enhances the thermal conductivity of the fluid. This conclusion has opened the best approach to utilize these new fluids in chemical engineering, mechanical designing, medicine, and many other fields.

As of late, the idea of a nanofluid has been proposed as a route for enhancing the execution of the heat transfer rates in the liquids. The investigation of heat generation or absorption parameter impacts on moving fluid is an important in view of several physical problems. Due to the quick development of electronic technology, effective cooling of electronic equipment towards becoming cooling of electronic equipment ranges and warranted from individual transistors to centralized server PCs and from energy suppliers to telephone switch boards. By considering temperature dependent heat generation / absorption, several authors have investigated the heat transfer problems. Copper nano particles of mean width less than $10 \mathrm{~nm}$, examined by Choi and Zhang (2001). Das et al., (2003) inspected a 2-4 fold rise in thermal conductivity development for nanofluid containing $\mathrm{TiO}_{2}-$ water nano particles over a small temperature vary from $21^{0}-51^{\circ} \mathrm{C}$. The existing literature demonstrated that ensures the enlargement of nanoparticles in the base fluid may accomplish an essentially reducing in the heat transfer; for comprehensive review, see [Mankinde and Aziz (2011), Khan and Pop (2010) and Nadeem and Haq (2014)]. Thermal conductivity of the nanofluid $\mathrm{K}_{\mathrm{nf}}$ neatly discussed by Maxwell (1904). Flow in permeable media was considered through various examinations in the amidst recent decades. It has different applications in mechanical and chemical engineering, particularly in soil matrix heat exchangers, non-atomic waste, stringy protection insulation, ground water hydrology, energy efficient drying process and so forth. There has been 
an increasing enthusiasm in heat and fluid courses through porous media (Nield and Bejan (2006), Vafai (2005) and Nield and Kuznetsov (2009)).

Transpiration of a fluid through the bounding surface can significantly change the flow field. Well all is said in done; suction tends to enhance the skin friction whereas injection acts in the contrary way. Injection or withdrawal of fluid through a porous bounding wall is of general interest in practical problems including boundary layer control applications, for example, polymer fiber coating, film cooling and coating of wires. The procedure of suction and blowing has also its grandness in many engineering activities, for example, in the design of thrust bearing and radial diffusers, and thermal oil recuperation. Suction is applied to chemical processes to remove reactants. Blowing is utilized to add reactants, cool the surface, prevent corrosion or scaling and reduce the drag. The effect of thermal radiation on flow and heat transfer processes is of significant significance in the design of many propelled energy conversion systems operating at high temperature. Thermal radiation within such systems happens in view of the out flow by the hot walls and working fluid. Sandeep et al. (2016) have been studied Dual Solutions of Radiative MHD Nano liquid stream over an exponentially stretching sheet with heat generation/absorption. Whenever heat and mass transfer happens all in while in a moving fluid, the connection between the fluxes and the driving potentials is of intricate nature. It has been discovered that an energy flux can be generated not only temperature gradient but also by concentration gradient is called the diffusion-thermo effect. In perspective of significance of this diffusion-thermo effect, Jha and Singh(1990) examined the free convection and mass transfer flow about an infinite vertical plate moving impulsively in its own plane.

Several investigators have analyzed the effect of chemical reaction on the flow, heat and mass transfer in various perspectives. Kiran Kumar et al. (2015) have been examined in the direction of the temperature and concentration is assumed to be fluctuating with time. Venkataramanaiah et al. (2016) have been clarified the nano particle effect on MHD boundary layer flow of Williamson fluid over a stretching sheet. Ramya et al. (2016) have been researched the steady two-dimensional flow of a viscous nano-fluid of MHD flow for the boundary layer flow. Fekry et al. (2012) have been talked about the consistent state thermal boundary layer flow with nonlinearly stretching sheet in Nano-fluids. Haile and Shankar (2015) have been exhibited on heat and mass transfer qualities of a moving plate of nanofluids. Mohammad Mehdi Keshtekar et al. (2014) have been examined mixed convection MHD flow of nanofluid over a nonlinear stretching sheet with variable magnetic field. Vendabai et al. (2014) have been contemplated a nanofluid over a stretching surface with variable transport properties. Sastry (2015) has been seen that inclusion of the magnetic field parameter on the flow increased the temperature and decreased the velocity profiles concerned. Shehzad et al. (2015) have been developed convective mass condition at the surface in flow analysis with nano particles. Anwar et al. (2013) have been considered on a nanofluid with the simultaneous heat and mass transfer when the MHD stagnation point stream of a nanofluid porous stretching sheet. Turkyilmazoglu (2016) has been performed the time dependent flow past an impulsively began vertical infinite isothermal plate in a viscous electrically conducting natural convective incompressible nanofluid.

We investigated the MHD nanofluid heat and mass transfer flow past a semi infinite flat plate in the presence of first order chemical reaction, diffusion thermo, radiation absorption. The problem is solved by regular perturbation technique, as a result of which the computations could be performed with a high accuracy. The effects of different flow parameters on the velocity and temperature profiles were sketched and analyzed. In addition, the local skin-friction and the heat transfer rates are examined.

\section{ANALYSIS OF THE FLOW OF THE PROBLEM}

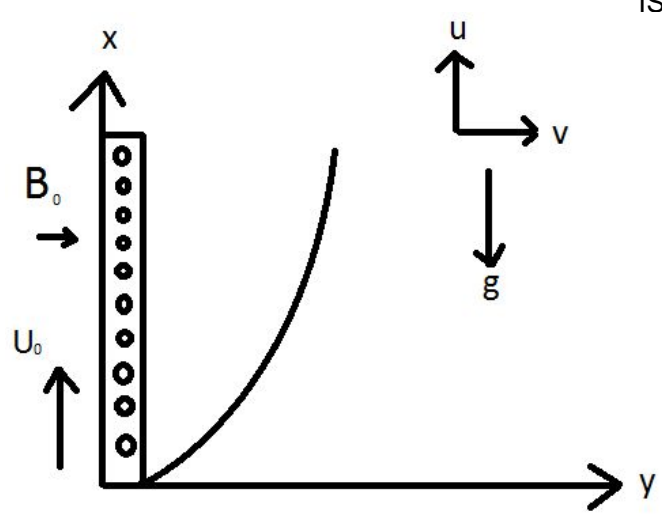

Fig.1 Physical Flow model diagram of the problem

An unsteady natural conventional flow of a nanofluid past a vertical permeable semi-infinite moving plate with constant heat source is considered. The physical model of the fluid flow is shown in Fig.1. The flow is assumed to be in the $\mathrm{x}$-direction which is taken along the plate and $y$-direction is normal to it. A uniform external field of strength $\mathrm{B}_{0}$ is taken to be acting along the y-direction. It is assumed that the induced magnetic field and the external electric field due to polarization of charges are negligible. The plate and the fluid are the same temperature $T_{\infty}^{\prime}$ and concentration $C_{\infty}^{\prime}$ in a stationary condition, when $\mathrm{t} \geq 0$, the temperature and concentration at the plate fluctuate with time harmonically from a constant mean. The fluid is a water based nanofluid containing four types of nano particles namely $\mathrm{Ag}$ (silver), $\mathrm{Al}_{2} \mathrm{O}_{3}$ (Aluminum Oxide), $\mathrm{Cu}$ (copper) and Titanium Oxide $\left(\mathrm{TiO}_{2}\right)$. The nano particles are assumed to have a uniform shape and size. Moreover, it is assumed that both the fluid phase nanoparticles are in thermal equilibrium state. Due to semi-infinite plate surface assumption, further more the flow variables are functions of $\mathrm{y}$ and $\mathrm{t}$ only.

$v^{\prime}=-V_{0}$, where the constant $-V_{0}$ represents the normal velocity at the plate which is positive suction $\left(V_{0}>0\right)$ and negative for blowing injection $\left(V_{0}<0\right)$.

Under the above boundary layer approximations, the governing equations Dharmaiah et al., (2017) for the nanofluid flow are given by

$\frac{\partial v^{\prime}}{\partial y^{\prime}}=0$

$\frac{\partial u^{\prime}}{\partial t^{\prime}}+v^{\prime} \frac{\partial u^{\prime}}{\partial y^{\prime}}=\frac{\mu_{n f}}{\rho_{n f}} \frac{\partial^{2} u^{\prime}}{\partial y^{\prime 2}}+\frac{(\rho \beta)_{n f}}{\rho_{n f}} g\left(T^{\prime}-T_{\infty}\right)-\frac{\mu_{n f}}{\rho_{n f}} \frac{u^{\prime}}{K^{\prime}}-\frac{1}{\rho_{n f}} \sigma B_{0}^{2} u^{\prime}$

$\left(\rho C_{p}\right)_{n f}\left(\frac{\partial T^{\prime}}{\partial t^{\prime}}+v^{\prime} \frac{\partial T^{\prime}}{\partial y^{\prime}}\right)=\alpha_{n f}\left(\rho C_{p}\right)_{n f} \frac{\partial^{2} T^{\prime}}{\partial y^{\prime 2}}-Q^{\prime}\left(T^{\prime}-T_{\infty}^{\prime}\right)+$

$Q_{l}^{\prime}\left(\rho C_{p}\right)_{n f}\left(C^{\prime}-C_{\infty}^{\prime}\right)+\frac{D_{m} K_{T}}{C_{s}} \frac{\partial^{2} C^{\prime}}{\partial y^{\prime 2}}$

$\frac{\partial C^{\prime}}{\partial t^{\prime}}+v^{\prime} \frac{\partial C^{\prime}}{\partial y^{\prime}}=D_{B} \frac{\partial^{2} C^{\prime}}{\partial y^{\prime 2}}-K_{l}\left(C^{\prime}-C_{\infty}^{\prime}\right)$

The relevant boundary conditions for the problem are given by

$$
\begin{aligned}
& t^{\prime}<0, \quad u^{\prime}\left(y^{\prime}, t^{\prime}\right)=0, \quad T^{\prime}=T_{\infty}^{\prime}, C^{\prime}=C_{\infty}^{\prime} \\
& t^{\prime} \geq 0, \quad u^{\prime}\left(y^{\prime}, t^{\prime}\right)=U_{0}, T^{\prime}=T^{\prime}{ }_{w}+\varepsilon e^{i w^{\prime} t^{\prime}}\left(T^{\prime}{ }_{w}-T_{\infty}^{\prime}\right), C^{\prime}=C^{\prime}{ }_{w}+\varepsilon e^{i w^{\prime} t^{\prime}}\left(C_{{ }_{w}}^{\prime}-C_{\infty}^{\prime}\right) \text { at } y^{\prime}=0 \\
& u^{\prime}\left(y^{\prime}, t^{\prime}\right)=0, \quad T^{\prime}=T_{\infty}^{\prime}, C^{\prime}=C_{\infty}^{\prime} \quad \text { as } y^{\prime} \rightarrow \infty
\end{aligned}
$$

The dimension less parameters feature in Equations

$(1)-(5)$ and are defined as:

$\operatorname{Pr}=\frac{v_{f}}{\alpha_{f}} ; K=\frac{K^{\prime} \rho_{f} U_{0}^{2}}{v_{f}^{2} \mu_{n f}} ; S=\frac{V_{0}}{U_{0}} ; M=\frac{\sigma B_{0}^{2} v_{f}}{\rho_{f} U_{0}^{2}} ;$

$S c=\frac{v_{f}}{D_{B}} ; G r=\frac{(\rho \beta)_{f} g v_{f}\left(T_{w}^{\prime}-T_{\infty}^{\prime}\right)}{\rho_{f} U_{0}^{2}} ;$ 


$$
\begin{aligned}
& D u=\frac{D_{m} K_{T}\left(C^{\prime}{ }_{w}-C_{\infty}^{\prime}\right)}{k_{f} C_{s}\left(T^{\prime}{ }_{w}-T_{\infty}^{\prime}\right)} ; u=\frac{u^{\prime}}{U_{0}} ; y=\frac{U_{0} y^{\prime}}{v_{f}} ; \\
& t=\frac{U_{0}^{2} t^{\prime}}{v_{f}} ; \theta=\frac{\left(T^{\prime}-T_{\infty}^{\prime}\right)}{\left(T^{\prime}{ }_{w}-T_{\infty}^{\prime}\right)} ; Q_{L}=\frac{Q_{l}^{\prime}\left(C^{\prime}{ }_{w}-C_{\infty}^{\prime}\right)}{U_{0}^{2}\left(T^{\prime}{ }_{w}-T_{\infty}^{\prime}\right)} ; \\
& K r=\frac{K_{l} v_{f}}{U_{0}^{2}} ; \psi=\frac{\left(C^{\prime}-C_{\infty}^{\prime}\right)}{\left(C^{\prime}{ }_{w}-C_{\infty}^{\prime}\right)} .
\end{aligned}
$$

.In equations (2) - (4) with the boundary conditions (5) we obtain

$$
\frac{\partial u}{\partial t}-S \frac{\partial u}{\partial y}=\frac{D}{A} \frac{\partial^{2} u}{\partial y^{2}}+\frac{B}{A} G r \theta-\left(M+\frac{1}{K}\right) u
$$

$\frac{\partial \theta}{\partial t}-S \frac{\partial \theta}{\partial y}-Q_{L} \psi=\frac{1}{C \operatorname{Pr}}\left(E \frac{\partial^{2} \theta}{\partial y^{2}}-Q \theta\right)+\frac{D u}{C \operatorname{Pr}} \frac{\partial^{2} \psi}{\partial y^{2}}$

$S c \frac{\partial \psi}{\partial t}-S c S \frac{\partial \psi}{\partial y}=\frac{\partial^{2} \psi}{\partial y^{2}}-S c K r \psi$

The corresponding boundary conditions are

$$
\begin{aligned}
t<0: u & =0, \theta=0, \psi=0 \\
t \geq 0: u & =1, \theta=1+\varepsilon e^{i w t}, \psi=1+\varepsilon e^{i w t} \quad \text { at } \quad y=0 \\
u & =0, \theta=0, \psi=0 \text { as } y \rightarrow \infty
\end{aligned}
$$

\section{NUMERICAL SOLUTIONS BY TWO TERM PERTURBATION TECHNIQUE}

Equations (6) - (8) are coupled non-linear partial differential equations whose solutions in closed-form are difficult to obtain. To solve these equations by converting into ordinary differential equations, the unsteady flow is superimposed on the mean steady flow, so that in the neighborhood of the plate, the expressions for velocity, temperature and concentration are assumed as

$$
\begin{aligned}
& u(y)=u_{0}(y)+\varepsilon e^{i w t} u_{1}(y)+O\left(\varepsilon^{2}\right) \\
& \theta(y)=\theta_{0}(y)+\varepsilon e^{i w t} \theta_{1}(y)+O\left(\varepsilon^{2}\right) \\
& \psi(y)=\psi_{0}(y)+\varepsilon e^{i w t} \psi_{1}(y)+O\left(\psi^{2}\right)
\end{aligned}
$$

Where $\varepsilon<<1$ is a perturbation parameter.

Now substituting equations (10) - (12) into equations (6) - (8) and equating the harmonic and non-harmonic terms and neglecting higher order terms, using relevant boundary conditions, we obtain the expressions for velocity, temperature and concentration as

$u(y, t)=\left(L_{5} e^{-m_{5} y}+L_{3} e^{-m_{3} y}+L_{4} e^{-m_{1} y}\right)+\varepsilon e^{i w t}\left(L_{8} e^{-m_{6} y}+L_{6} e^{-m_{4} y}+L_{7} e^{-m_{2} y}\right)$

$\theta(y, t)=\left(L_{1} e^{-m_{3} y}+A_{1} e^{-m_{1} y}\right)+\varepsilon e^{i w t}\left(L_{2} e^{-m_{4} y}+A_{2} e^{-m_{2} y}\right)$

$\psi(y, t)=e^{-m_{1} y}+\varepsilon e^{i w t} e^{-m_{2} y}$

The dimensionless skin-friction coefficient, rate of heat transfer and rate of mass transfer are given by

$\tau=-\left(\frac{\partial u}{\partial y}\right)_{y=0}=\left(L_{5} m_{5}+L_{3} m_{3}+L_{4} m_{1}\right)+\varepsilon e^{i w t}\left(L_{8} m_{6}+L_{6} m_{4}+L_{7} m_{2}\right)$

$N u=-\left(\frac{\partial \theta}{\partial y}\right)_{y=0}=\left(L_{1} m_{3}+A_{1} m_{1}\right)+\varepsilon e^{i w t}\left(L_{2} m_{4}+A_{2} m_{2}\right)$
$S h=-\left(\frac{\partial \psi}{\partial y}\right)_{y=0}=m_{1}+\varepsilon e^{i w t} m_{2}$

\section{RESULTS AND DISCUSSIONS}

In order to bring out the silent features of the flow, heat and mass transfer characteristics with nanoparticles, the results are presented in Figures 2-6 and Tables 1-2. The influences of nanoparticles on the velocity, the temperature and the concentration distributions as well as on the skin-friction, the heat transfer rate and mass transfer rate are discussed numerically. We have assumed here $\varepsilon=0.01, \mathrm{t}=1, \omega=1$ and $\operatorname{Pr}=6.785$, while the remaining parameters are varied over a range.

\subsection{Variations of the Velocity Distribution and skin-friction coefficient}

Figures 2(a), 2(b), 2(c) and 2(d) shows the effect of suction parameter S on fluid velocity $\mathrm{u}$ for both regular $(\phi=0)$ and nano fluid $(\phi \neq 0)$. As output of figures, it is seen that the velocity of the fluid across the boundary layer by increasing the suction parameter $\mathrm{S}$ for both regular and nano fluid with Nano particles $\mathrm{Ag}, \mathrm{Al}_{2} \mathrm{O}_{3}, \mathrm{Cu}$ and $\mathrm{TiO}_{2}$. It is worth said here that the influence of the suction parameter $\mathrm{S}$ on the fluid velocity is more effective for Alu water nanofluid than that of $\mathrm{Ag}$ water nanofluid and $\mathrm{Cu}$ water nanofluid. Hence, momentum boundary layer thickness decreases. Figure 3(a), 3(b), 3(c) and 3(d) witnessed the influence of radiation absorption parameter $\mathrm{Q}_{\mathrm{L}}$ on velocity distribution. It is clear from the figures that velocity increase with increase of $\mathrm{Q}_{\mathrm{L}}$ within the boundary layer as well as an increase in the momentum, because the large values of $\mathrm{Q}_{\mathrm{L}}$ correspond to the increased domination of conduction over absorption radiation, thereby increasing buoyancy force and momentum boundary layer. The magnetic parameter $\mathrm{M}$ on velocity profiles for Nano particles $\mathrm{Ag}, \mathrm{Al}_{2} \mathrm{O}_{3}, \mathrm{Cu}$ and $\mathrm{TiO}_{2}$ are appeared in figures 4(a), 4(b), 4(c) and 4(d). From these graphs, clearly, nanofluid velocity of the fluid decelerates with an increase in the strength of magnetic field. The impacts of a transverse magnetic field on an electrically, conducting fluid give ascent to a resistive-type force called the Lorentz force. This force has the tendency to slow down the motion of the fluid in the boundary layer. It is clear that, retardation in the velocity of the fluid and an increment in its boundary layer thickness. The numerical estimations of the skin-friction coefficient for the nanoparticles $\mathrm{Ag}, \mathrm{Al}_{2} \mathrm{O}_{3}, \mathrm{Cu}$ and $\mathrm{TiO}_{2}$ are in Table 1. From this table, it is seen that the skin-friction coefficient enhances with increase values of $\mathrm{S}$ and $\mathrm{M}$ while decrease with increase values of $\mathrm{Du}, \mathrm{Q}_{\mathrm{L}}, \mathrm{Pr}$, $\mathrm{Sc}$ and $\mathrm{K}$ for the four nanoparticles $\mathrm{Ag}, \mathrm{Al}_{2} \mathrm{O}_{3}, \mathrm{Cu}$ and $\mathrm{TiO}_{2}$.

\subsection{Variations of the Temperature Distribution and heat}

\section{transfer rate}

The influence of Diffusion Thermo parameter Du on the temperature distribution for $\mathrm{Ag}$-water, $\mathrm{Al}_{2} \mathrm{O}_{3}$-water, $\mathrm{Cu}$ water and $\mathrm{TiO}_{2}$-water nano fluids is depicted in figures 5(a), 5(b), 5(c)and 5(d) with in boundary layer. With the increasing values of $\mathrm{Du}$, the temperature of nanofluid is found to enhance the thermal boundary layer thickness. Thermal boundary layer thickness is high. Physically, the Dufour term that appears in the temperature equation measures the contribution of concentration gradient to thermal energy flux in the flow domain. It has a vital role in enhancing the flow velocity and the ability to increase the thermal energy in the boundary layer. As result, the temperature profile increases with the increase of Du.

The graphical representation of prandtl number Pr on temperature profiles as depicted in figures 6(a), 6(b), 6(c) and 6(d) with in boundary layer. Prandtl number characterizes the relative adequacy of the momentum transport by dispersion in the hydrodynamic boundary layer to the essentialness transported by thermal dispersion in the thermal boundary layer. As demonstrated by the importance of Prandtl number higher Pr liquids have bought down thermal conductivities which dimi- 


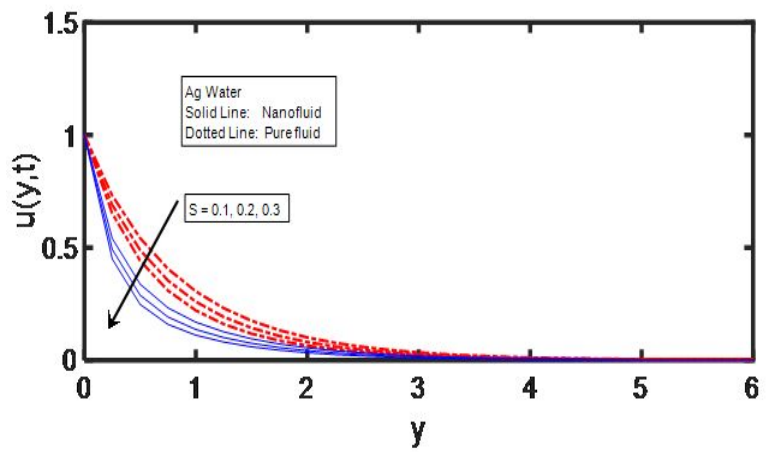

Fig. 2(a) Plot of suction parameter(S) on velocity profile with Ag-Water.

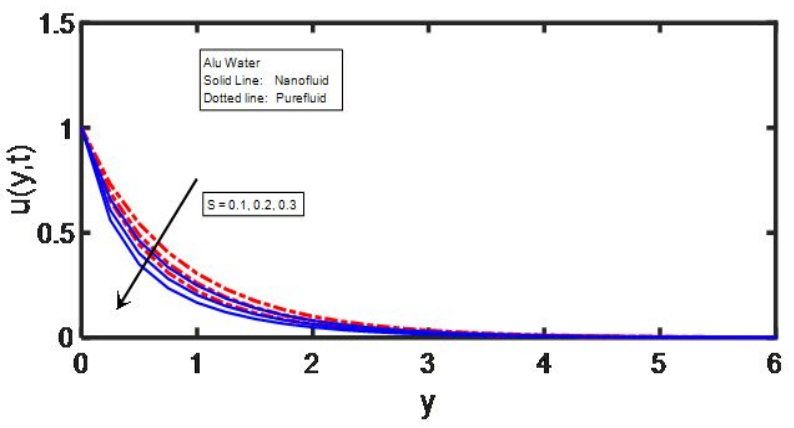

Fig. 2(b) Plot of suction parameter(S) on velocity profile with Alu-water.

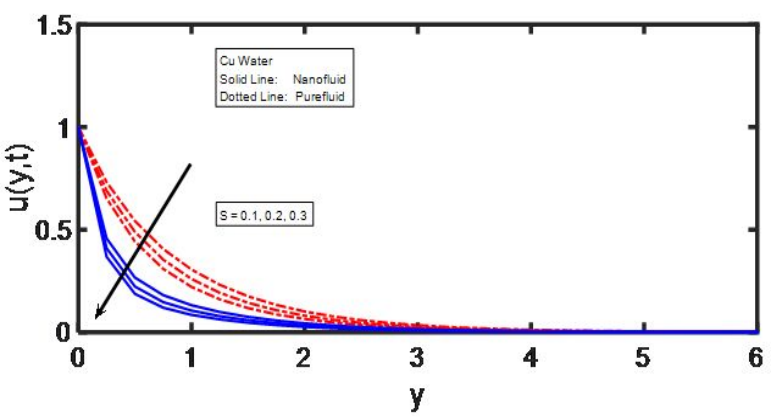

Fig. 2(c) Plot of suction parameter(S) on velocity profile with $\mathrm{Cu}$-water

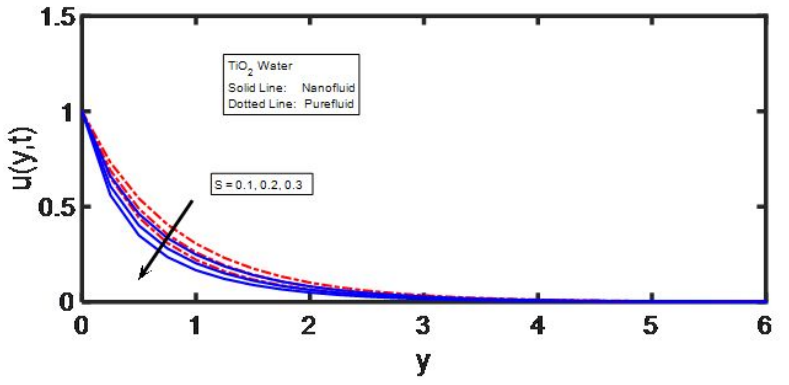

Fig. 2(d) Plot of suction parameter(S) on velocity profile with $\mathrm{TiO}_{2}$-water.

-ishes the conduction heat transfer and increments temperature assortments that an expansion in Pr achieves decreasing temperature dispersion, since; thermal boundary layer thickness reduces with increasing values of Pr. Table 2. Indicates the numerical values of heat transfer rate for different fluid flow parameters $\mathrm{Du}, \phi, \mathrm{Q}_{\mathrm{L}}$ and $\mathrm{Q}$ for $\mathrm{Ag}$ water, $\mathrm{Al}_{2} \mathrm{O}_{3}$ water, $\mathrm{Cu}$ water and $\mathrm{TiO}_{2}$ water nanofluids.

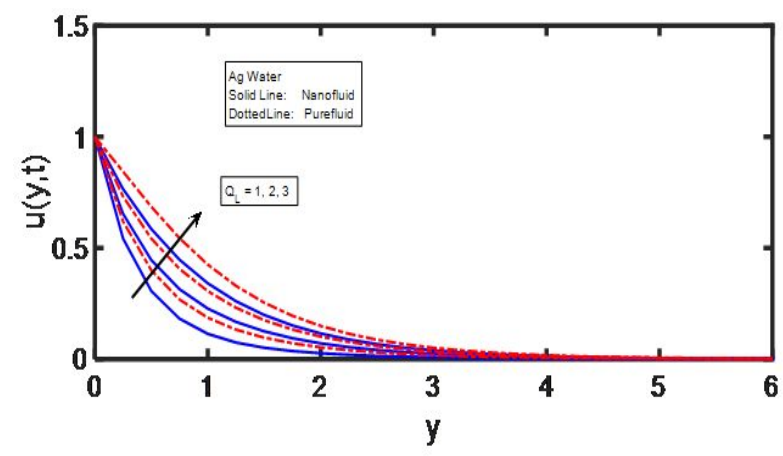

Fig. 3(a) Plot of radiation absorption parameter $\left(\mathrm{Q}_{\mathrm{L}}\right)$ on Velocity profile with $\mathrm{Ag}$-water.

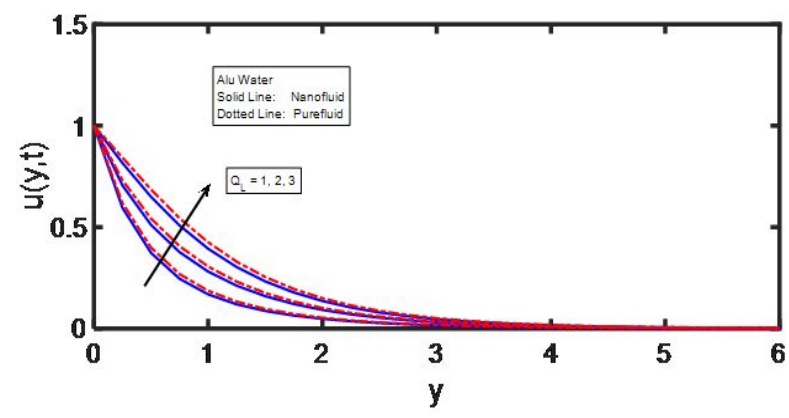

Fig.3 (b) Plot of radiation absorption parameter $\left(\mathrm{Q}_{\mathrm{L}}\right)$ on velocity Profile with Alu-water.

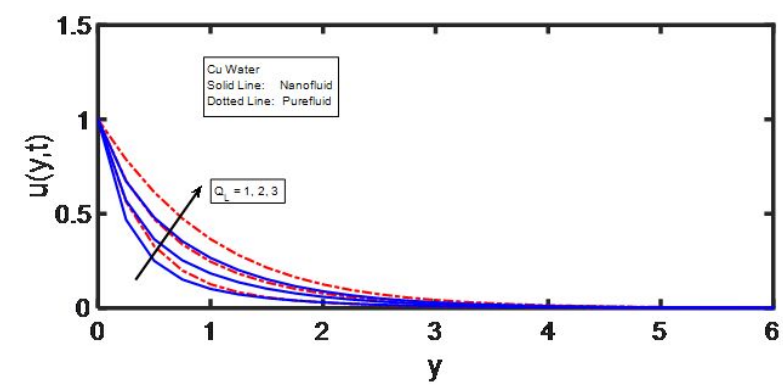

Fig. 3(c) Plot of radiation absorption parameter $\left(\mathrm{Q}_{\mathrm{L}}\right)$ on velocity Profile with $\mathrm{Cu}$-water.

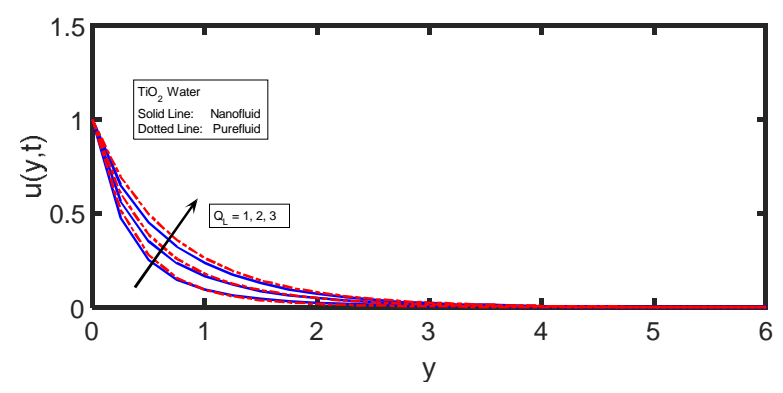

Fig. 3(d) Plot of radiation absorption parameter $\left(\mathrm{Q}_{\mathrm{L}}\right)$ on velocity profile with $\mathrm{TiO}_{2}$-water.

From this table obviously the heat transfer rate increases with $\phi$ and $\mathrm{Q}$, while diminishes with $\mathrm{Du}$ and $\mathrm{Q}_{\mathrm{L}}$. It was observed that after adding nano particles, the mass transfer rate significantly increases up to twofold. Furthermore the results indicate that under the circumstances in which the mass flow rate is high enough, the effect of nano particles on the mass transfer phenomenon is too slight. Due to brevity, we have not discussed more. 


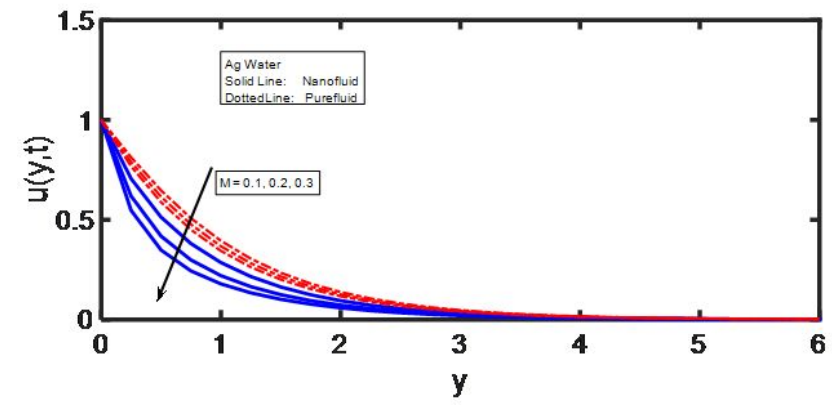

Fig. 4(a) Plot of magnetic parameter (M) on velocity profile With Ag-water.

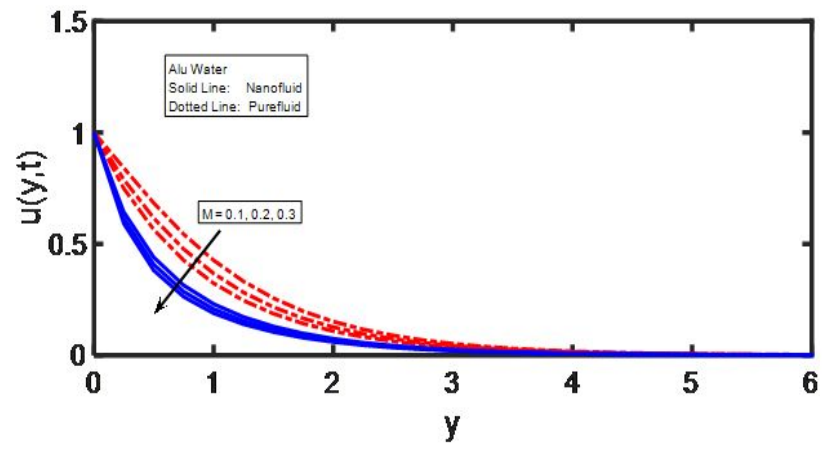

Fig. 4(b) Plot of magnetic parameter (M) on velocity profile with Alu-water.

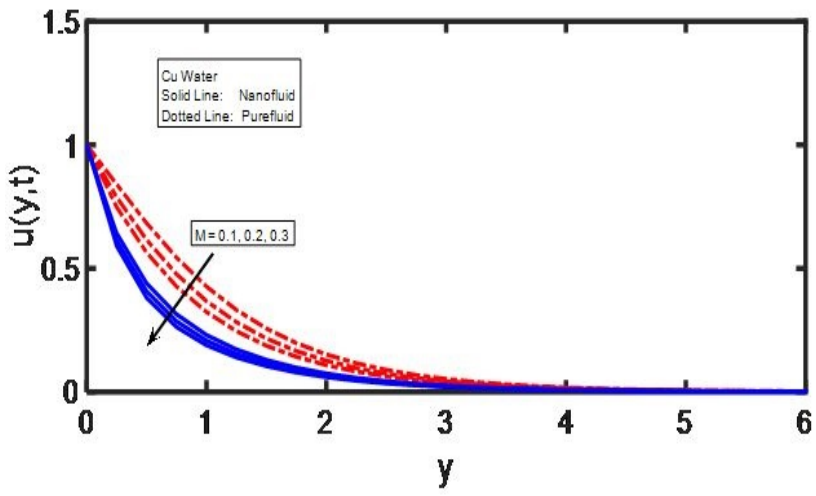

Fig. 4(c) Plot of magnetic parameter (M) on velocity profile with $\mathrm{Cu}$-water.

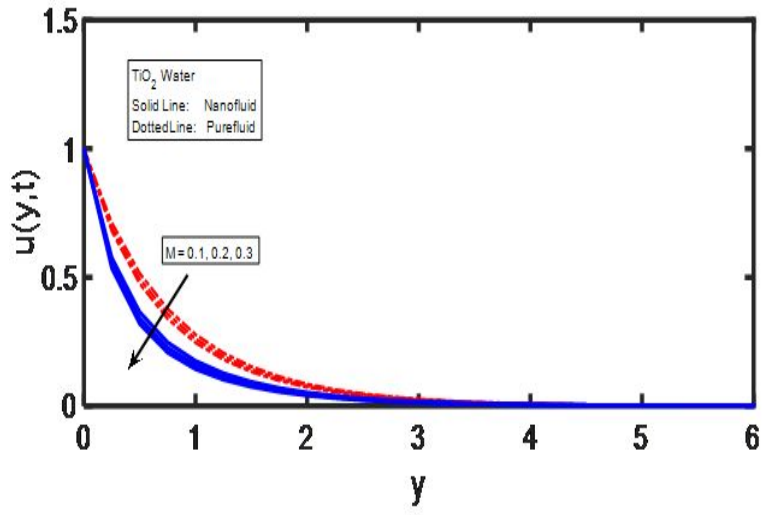

Fig. 4(d) Plot of magnetic parameter (M) on velocity profile with $\mathrm{TiO}_{2}$-water.

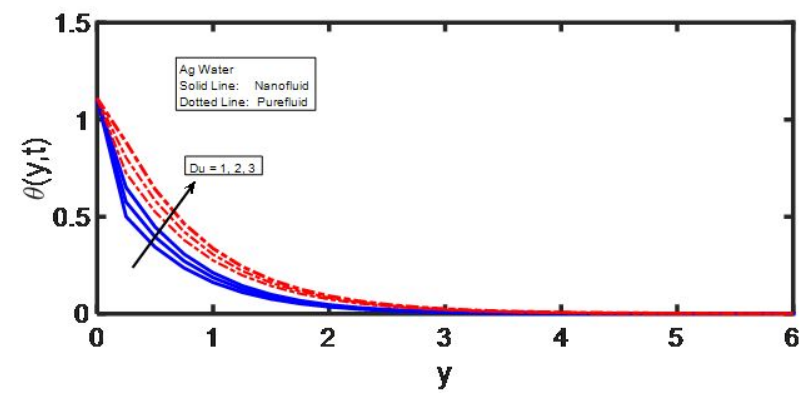

Fig. 5(a) Plot of Dufour number (Du) on temperature profile with Ag-water.

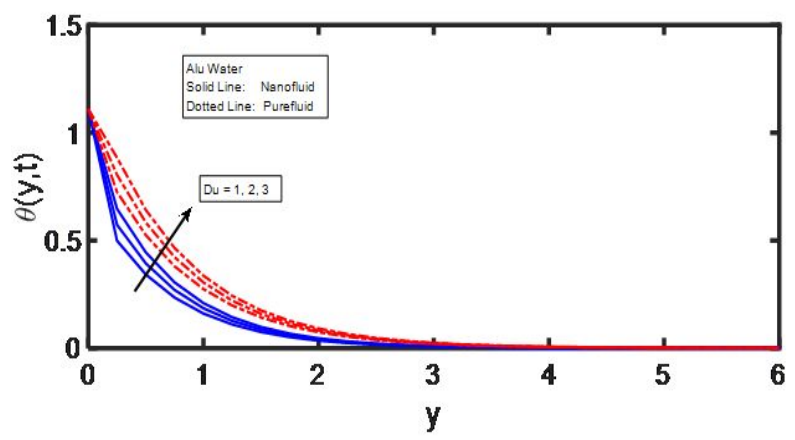

Fig. 5(b) Plot of Dufour number (Du) on temperature profile with Alu-water.

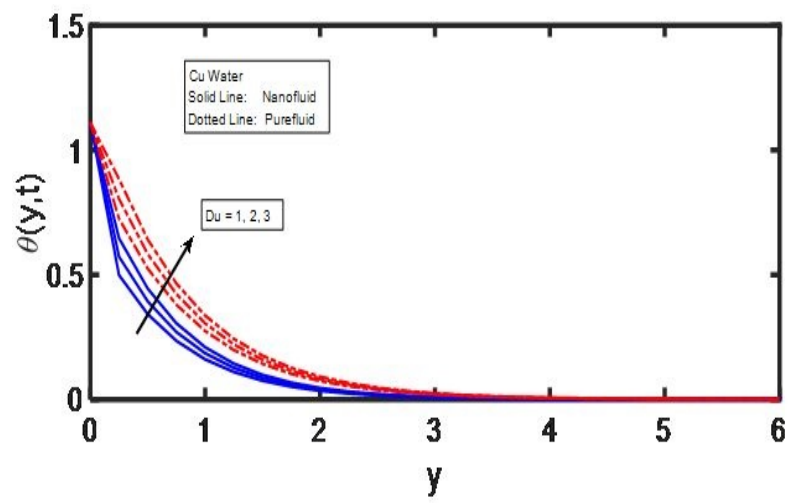

Fig. 5(c) Plot of Dufour number (Du) on temperature profile with $\mathrm{Cu}$-water.

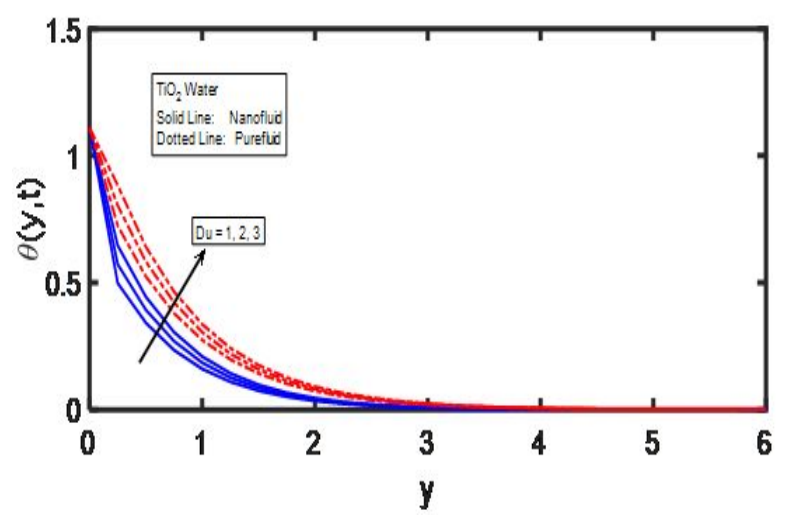

Fig. 5(d) Plot of Dufour number (Du) on temperature profile with $\mathrm{TiO}_{2}$-water. 


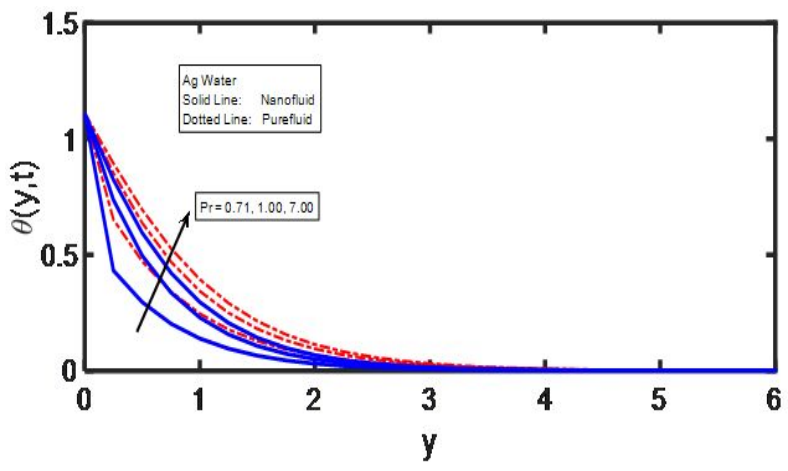

Fig. 6(a) Plot of Prandtl number (Pr) on temperature profile with Ag-water

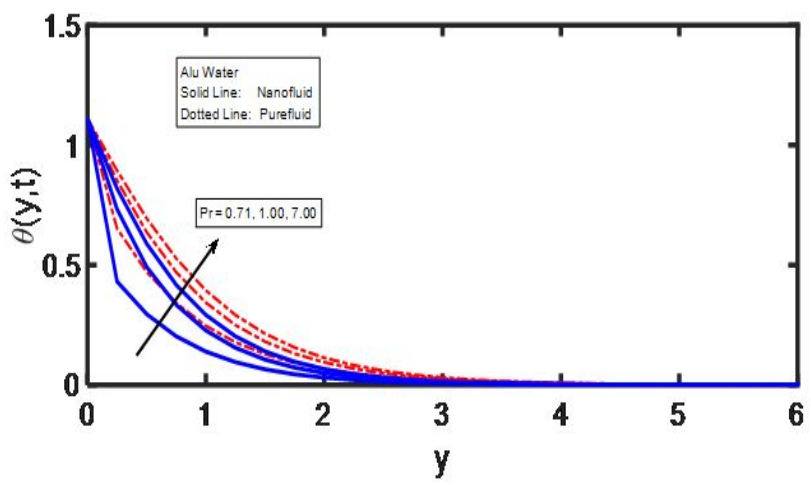

Fig. 6(b) Plot of Prandtl number (Pr) on temperature profile with Alu-water.

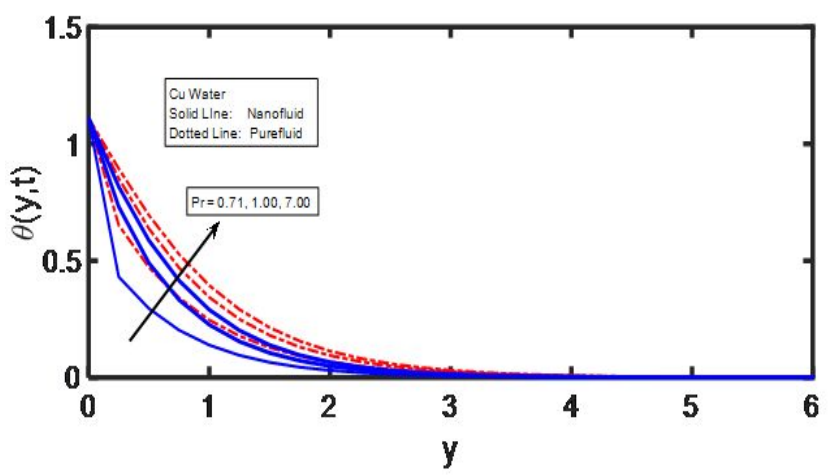

Fig. 6(c) Plot of Prandtl number (Pr) on temperature profile with $\mathrm{Cu}$-water.

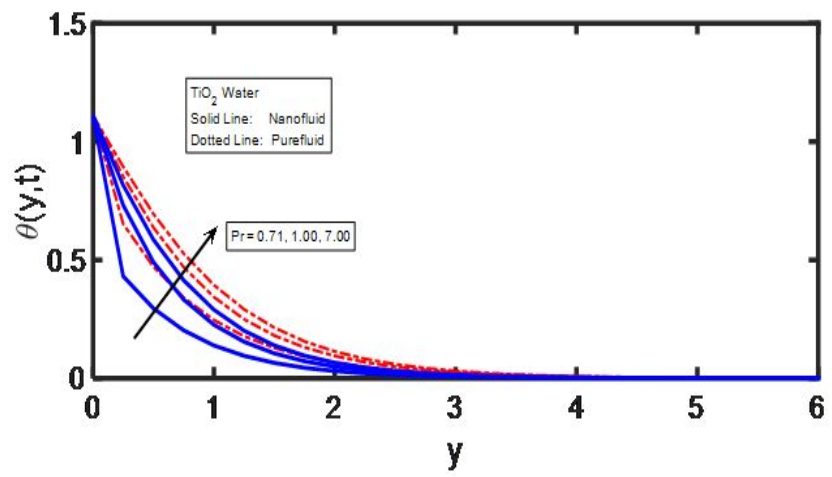

Fig. 6(d) Plot of Prandtl number (Pr) on temperature profile with $\mathrm{TiO}_{2}$-water.
Table 1 Comparison of skin-friction coefficient values among $\mathrm{Ag}, \mathrm{Alu}, \mathrm{Cu}$ and $\mathrm{TiO}_{2}$

\begin{tabular}{|c|c|c|c|c|c|c|c|c|c|c|}
\hline $\mathrm{S}$ & $\mathrm{Du}$ & $\mathrm{M}$ & $\mathrm{QL}$ & $\mathrm{Sc}$ & $\mathrm{Pr}$ & $\mathrm{K}$ & $\mathrm{Ag}$ & $\mathrm{Alu}$ & $\mathrm{Cu}$ & $\mathrm{TiO}_{2}$ \\
\hline $\mathbf{0 . 1}$ & 0.5 & 0.5 & 2 & 0.30 & 6.785 & 4 & 0.4734 & 0.5043 & 0.4838 & 0.5036 \\
$\mathbf{0 . 2}$ & 0.5 & 0.5 & 2 & 0.30 & 6.785 & 4 & 0.6388 & 0.5786 & 0.6530 & 0.5824 \\
$\mathbf{0 . 3}$ & 0.5 & 0.5 & 2 & 0.30 & 6.785 & 4 & 0.8563 & 0.7161 & 0.8037 & 0.7277 \\
0.1 & $\mathbf{0 . 2}$ & 0.5 & 2 & 0.30 & 6.785 & 4 & 0.4769 & 0.5068 & 0.4871 & 0.5061 \\
0.1 & $\mathbf{0 . 3}$ & 0.5 & 2 & 0.30 & 6.785 & 4 & 0.4758 & 0.5060 & 0.4860 & 0.5053 \\
0.1 & $\mathbf{0 . 4}$ & 0.5 & 2 & 0.30 & 6.785 & 4 & 0.4746 & 0.5051 & 0.4849 & 0.5044 \\
0.1 & 0.5 & $\mathbf{0 . 1}$ & 2 & 0.30 & 6.785 & 4 & 1.3663 & 0.6351 & 1.1182 & 0.6548 \\
0.1 & 0.5 & $\mathbf{0 . 2}$ & 2 & 0.30 & 6.785 & 4 & 1.4892 & 0.6691 & 1.2039 & 0.6903 \\
0.1 & 0.5 & $\mathbf{0 . 3}$ & 2 & 0.30 & 6.785 & 4 & 1.6393 & 0.7061 & 1.3051 & 0.7292 \\
0.1 & 0.5 & 0.5 & $\mathbf{1}$ & 0.30 & 6.785 & 4 & 0.7002 & 0.6667 & 0.6937 & 0.6685 \\
0.1 & 0.5 & 0.5 & $\mathbf{2}$ & 0.30 & 6.785 & 4 & 0.2466 & 0.3419 & 0.2740 & 0.3387 \\
0.1 & 0.5 & 0.5 & $\mathbf{3}$ & 0.30 & 6.785 & 4 & 0.0198 & 0.1794 & 0.0641 & 0.1738 \\
0.1 & 0.5 & 0.5 & 2 & $\mathbf{0 . 2 2}$ & 6.785 & 4 & 0.4955 & 0.5695 & 0.5159 & 0.5710 \\
0.1 & 0.5 & 0.5 & 2 & $\mathbf{0 . 3 2}$ & 6.785 & 4 & 0.4497 & 0.4874 & 0.4614 & 0.4863 \\
0.1 & 0.5 & 0.5 & 2 & $\mathbf{0 . 4 2}$ & 6.785 & 4 & 0.2155 & 0.2589 & 0.2287 & 0.2576 \\
0.1 & 0.5 & 0.5 & 2 & 0.30 & $\mathbf{0 . 7 1 0}$ & 4 & 0.8685 & 0.7873 & 0.8495 & 0.7909 \\
0.1 & 0.5 & 0.5 & 2 & 0.30 & $\mathbf{1 . 0 0 0}$ & 4 & 0.8470 & 0.7725 & 0.8297 & 0.7758 \\
0.1 & 0.5 & 0.5 & 2 & 0.30 & $\mathbf{7 . 0 0 0}$ & 4 & 0.4611 & 0.4951 & 0.4723 & 0.4943 \\
0.1 & 0.5 & 0.5 & 2 & 0.30 & 6.785 & $\mathbf{1}$ & 0.9672 & 0.9414 & 0.9636 & 0.9431 \\
0.1 & 0.5 & 0.5 & 2 & 0.30 & 6.785 & $\mathbf{2}$ & 0.6710 & 0.6700 & 0.6741 & 0.6707 \\
0.1 & 0.5 & 0.5 & 2 & 0.30 & 6.785 & $\mathbf{3}$ & 0.5811 & 0.5925 & 0.5991 & 0.5932 \\
\hline
\end{tabular}

Table 2 Comparison of rate of heat transfer values among $\mathrm{Ag}, \mathrm{Alu}, \mathrm{Cu}$ and $\mathrm{TiO}_{2}$

\begin{tabular}{|c|c|c|c|r|r|r|r|}
\hline $\mathrm{Du}$ & $\phi$ & $\mathrm{QL}$ & $\mathrm{Q}$ & \multicolumn{1}{c|}{$\mathrm{Ag}$} & \multicolumn{1}{c|}{$\mathrm{Alu}$} & \multicolumn{1}{c|}{$\mathrm{Cu}$} & \multicolumn{1}{c|}{$\mathrm{TiO}_{2}$} \\
\hline $\mathbf{0 . 2}$ & 0.10 & 2 & 1 & 0.2412 & 0.2418 & 0.2369 & 0.2542 \\
$\mathbf{0 . 3}$ & 0.10 & 2 & 1 & 0.0713 & 0.0719 & 0.0669 & 0.0844 \\
$\mathbf{0 . 4}$ & 0.10 & 2 & 1 & -0.0985 & -0.0981 & -0.1032 & -0.0854 \\
0.1 & $\mathbf{0 . 0 5}$ & 2 & 1 & 0.4073 & 0.4076 & 0.4052 & 0.4140 \\
0.1 & $\mathbf{0 . 1 0}$ & 2 & 1 & 0.4111 & 0.4117 & 0.4069 & 0.4240 \\
0.1 & $\mathbf{0 . 1 5}$ & 2 & 1 & 0.4150 & 0.4157 & 0.4086 & 0.4336 \\
0.1 & $\mathbf{0 . 2 0}$ & 2 & 1 & 0.4188 & 0.4197 & 0.4104 & 0.4428 \\
0.1 & 0.10 & $\mathbf{1}$ & 1 & 8.5465 & 8.6655 & 8.7470 & 8.6465 \\
0.1 & 0.10 & $\mathbf{3}$ & 1 & 7.7243 & -7.8421 & -7.9332 & -8.3078 \\
0.1 & 0.10 & $\mathbf{4}$ & 1 & -15.8597 & -16.0959 & -16.2733 & -16.5303 \\
0.1 & 0.10 & 2 & $\mathbf{2}$ & 1.6279 & 1.6292 & 1.6256 & 1.6396 \\
0.1 & 0.10 & 2 & $\mathbf{3}$ & 2.6894 & 2.6931 & 2.6918 & 2.7016 \\
0.1 & 0.10 & 2 & $\mathbf{4}$ & 3.6254 & 3.6326 & 3.6342 & 3.6390 \\
\hline
\end{tabular}

Table 3 Thermo physical properties of fluid and nanoparticles given by Oztop and Abu-Nada (2008).

\begin{tabular}{|l|l|l|l|l|l|}
\hline $\begin{array}{l}\text { Physical } \\
\text { properties }\end{array}$ & water & $\mathrm{Cu}$ & $\mathrm{Al}_{2} \mathrm{O}_{3}$ & $\mathrm{TiO}_{2}$ & $\mathrm{Ag}$ \\
\hline $\mathrm{C}_{\mathrm{p}}(\mathrm{J} / \mathrm{kgK})$ & 4179 & 385 & 765 & 686.2 & 235 \\
\hline$\rho\left(\mathrm{kg} / \mathrm{m}^{3}\right)$ & 997.1 & 8933 & 3970 & 4250 & 10500 \\
\hline $\mathrm{k}(\mathrm{W} / \mathrm{mK})$ & 0.613 & 400 & 40 & 8.9538 & 429 \\
\hline$\beta \mathrm{X} 10^{-5}$ & 21 & 1.67 & 0.85 & 0.9 & 1.89 \\
\hline
\end{tabular}

\section{CONCLUSIONS}

We have performed Analysis of Heat and Mass Transfer on MHD flow with $\mathrm{Ag}, \mathrm{Al}_{2} \mathrm{O}_{3}, \mathrm{Cu}$ and $\mathrm{TiO}_{2}$ Water Nanofluids over a Semi Infinite Flat Surface. In this article we considered Ag-water, Alu-water, $\mathrm{Cu}$ water and $\mathrm{TiO}_{2}$ Water nanofluids. We have solved the model equations using regular perturbation technique. The following conclusions can be made from the present investigation.

$>$ The silver (Ag) nanoparticles proved to have the maximum cooling recital for this vertical porous plate problem. This is due to the high thermal conductivity of $\mathrm{Ag}$ and low thermal conductivity of $\mathrm{Al}_{2} \mathrm{O}_{3}$, $\mathrm{Cu}$ and $\mathrm{TiO}_{2}$. 
absorption parameter number.

$>$ The temperatures profile increases with an increase in Dufour

$>$ The heat transfer rate increases as Q increases.

$>$ The skin-friction coefficient diminishes as Pr enhances.

\section{NOMENCLATURE}

$\mathrm{x}, \mathrm{y} \quad$ - cartesian coordinates $(\mathrm{m})$

$\mathrm{u}^{\prime}, \mathrm{v}^{\prime}$ - velocity components along the $\mathrm{x}$ and $\mathrm{y}$ axes $(\mathrm{m} / \mathrm{s})$

Q - temperature dependent volumetric rate of the heat source

$\beta_{\mathrm{nf}} \quad$ - coefficient of thermal expansion of nanofluid

$\mu_{\mathrm{nf}} \quad$ - viscosity of nanofluid

$\left(\rho C_{p}\right)_{n f} \quad$ - heat capacitance of the nanofluid

$\mathrm{g} \quad$ - acceleration due to gravity

$\mathrm{K}^{\prime} \quad$ - permeability porous medium

$\mathrm{T}^{\prime} \quad$ - temperature of the nanofluid $(\mathrm{K})$

$\alpha_{\mathrm{nf}} \quad$ - thermal diffusivity of the nanofluid

$\mathrm{K}_{\mathrm{nf}} \quad$ - thermal conductivity of the base fluid

$\mathrm{K}_{\mathrm{s}} \quad$ - thermal conductivity of the solid

$\beta_{\mathrm{f}} \quad$ - coefficient of thermal expansion of the fluid

$\beta_{\mathrm{C}} \quad$ - coefficient of thermal expansion of the solid

$\rho_{\mathrm{f}} \quad$ - density of the fluid $\left(\mathrm{kgm}^{-3}\right)$

$\rho_{\mathrm{C}} \quad-$ density of the solid

$\rho_{\mathrm{nf}} \quad$ - viscosity of the nanofluid

$\mathrm{Pr} \quad$ - prandtl number

K - permeability parameter

$\mathrm{S} \quad$ - suction $(\mathrm{S}>0)$ or Injection $(\mathrm{S}<0)$ parameter

M - magnetic parameter

Sc - schmidt number

Gr - grashof number

$\mathrm{Du} \quad$ - diffusion-thermo parameter

$\mathrm{t} \quad$ - dimensional time(s)

$\mathrm{Q}_{\mathrm{L}} \quad$ - radiation absorption parameter

$\mathrm{Kr} \quad-$ chemical reation parameter

\section{Greek Symbols}

$\phi \quad$ - solid volume fraction of the nanoparticles

$\psi \quad$ - dimensionless concentration

$\theta \quad$ - dimensionless temperature $(\mathrm{k})$

\section{REFERENCES}

Ali, F. Md., Nazar, R., Arfin, N. Md., Pop, I., 2010, "MHD Boundary Layer Flow and Heat Transfer over a Stretching Sheet with Induced Magnetic Field," Heat and Mass transfer, 47(2), 155-162. https://doi.org/10.1007/s00231-010-0693-4

Choi, S.U.S., 1995, "Enhancing Thermal Conductivity of Fluids with Nanoparticles," In: Proceedings of the ASME International Mechanical Engineering Congress and Exposition, San Franscisco, USA. ASME, FED 231/MD, 66, 99-105.

Choi, S.U.S., Zhang, Z.G., Yu. W., Lockwood. F.E., Grulke. E.A., 2001, "Anomalous Thermal Conductivity Enhancement in Nanotube Suspensions," Applied Physics Letters, 79(14), 2252-2254.

https://doi.org/10.1063/1.1408272

Das, S.K., Putra, N., Thiesen, P., Roetzel, W., 2003, "Temperature Dependence of Thermal Conductivity Enhancement in Nanofluids," Journal of heat transfer, 12, 567-574. https://doi:10.1115/1.1571080.

Dharmaiah Gurram, Balamurugan, K.S., Venkateswarulu, M., 2017, "Analysis of Heat and Mass Transfer on MHD Flow of Nano Fluid over a Semi Infinite Moving Surface with Diffussion Thermo," SKIT Research Journal, 7(2), 79-87. ISSN: 2278-2508.

Ellahi, R., 2013, “The Effects of MHD and Temperature Dependent Viscosity on The Flow of Non-Newtonian Nanofluid in a Pipe: Analytic Solutions," Applied Mathematical modeling, 37, 1451-1467. https://doi.org/10.1016/j.apm.2012.04.004

Eshetu Haile, Shankar, B., 2015, "Boundary-Layer Flow of Nanofluids over a Moving Surface in the Presence of Thermal Radiation, Viscous Dissipation and Chemical Reaction," Applications and Applied Mathematics, 10(2), 952-969. ISSN: 1932-9466.

Fekry M Hady, Fouad S Ibrahim, Sahar M Abdel-Gaied, Mohamed R Eid, 2012, "Radiation Effect on Viscous Flow of Nano-Fluid and Heat Transfer over a Nonlinearly Stretching Sheet," Nanoscale Research Letters, Springer, 7, 1-13.

http://dx.doi.org/10.1186/1556-276X-7-229

Imran Anwar, Abdul Rahman Mohd Kasim, Zulkibri Ismail, Mohd Zuki Salleh, Sharidan Shafie, 2013, "Chemical Reaction and Uniform Heat Generation of Absorption Effects on MHD Stagnation-Point Flow of a Nanofluid over a Porous Sheet," World Applied Sciences Journal, 24(10), 1390-1398.

http://dx.doi.org/10.5829/idosi.wasj.2013.24.10.1307.

Jha B.K., Singh. A.K., (1990), "Soret Effect on Free Convection and Mass Transfer Flow in the Stokes Problem for an Infinite Vertical Plate," Astrophys Space sci., 173, 251-255.

http://dx.doi.org/10.1007/bf00643934

Khan, W.A., Pop. I., 2010, "Boundary-Layer Flow of a Nanofluid Past a Stretching Sheet," International Journal Heat Mass Transfer, 53, 2477-2483.

https://doi.org/10.1016/j.ijheatmasstransfer.2010.01.032.

Kiran Kumar. R.V.M.S.S., Durga Prasad, P., Varma, S.V.K., 2015, "Analytical Study of Heat and Mass Transfer Enhancement in Free Convection Flow with Chemical Reaction and Constant Heat Source in Nano-Fluids," Procedia Engineering, 127, 978-985.

http://dx.doi.org/10.1016/J.Proeng.2015.11.446.

Mabood, F., Khan, W.A., Ismail, A.I.M., 2015, "MHD Boundary Layer Flow and Heat Transfer of Nanofluids over a Nonlinear Stretching Sheet: A Numerical Study," Journal of Magnetism and Magnetic Materials, 374, 569-576.

https://doi.org/10.1016/j.jmmm.2014.09.013

Makinde, O.D., Aziz, A., 2011, "Boundary Layer Flow of a Nanofluid Past a Stretching Sheet with a Convective Boundary Condition," International Journal of thermal Science, 50(7), 1326-1332.

https://doi.org/10.1016/j.ijthermalsci.2011.02.019

Maxwell. J., 1904, A Treatise on Electricity and Magnetism, second ed., Oxford University Press, Cambridge, UK. ISBN: 9780198503736.

Mohammad Mehdi Keshtekar, Ahmad Khaluei, Hadi Ameri Fard, 2014, "Effects of Thermal Radiation, Viscous Dissipation, Variable Magnetic Field and Suction on Mixed Convection MHD Flow of Nano Fluid over a Nonlinear Stretching Sheet," IOSR journal of Engineering, 04, 44-54. ISSN: 2250-3021

Nadeem, S., Haq, R.U., 2014, "Effect of Thermal Radiation for Magneto-Hydrodynamic Boundary Layer Flow of a Nanofluid Past a Stretching Sheet with Convective Boundary Conditions," Journal of Computational and Theoretical Nanoscience, 11(1), 32-40.

https://doi.org/10.1166/jetn.2014.3313 
Nogrehabadi, A., Pourrajab, R., Ghalambaz, M., 2013, "Flow and Heat Transfer of Nanofluids over Stretching Sheet Taking into Account Partial Slip and Thermal Convective Boundary Conditions," Heat and Mass Transfer, 49(9), 1357-1366. https://doi.org/10.1007/s00231-013-1179-y

Nield, D.A., Bejan. A., 2006, Convection in porous media, $3^{\text {rd }}$ edn. Springer, New York. ISBN: 0387984437

Nield, D.A., Kuznetsov, A.V., 2009, "The Cheng Minkowycz Problem for Natural Convective Boundary-Layer Flow in a Porous Medium Saturated by a Nanofluid," International Journal of Heat and Mass Transfer, 52, 25-26.ISSN: 5792-5795

Oztop, H.F., and Abu-Nada, E., 2008, "Numerical Study of Natural Convection in partially Heated Rectangular Enclosures Filled with Nanofluid," Int.J.Heat Fluid Flow, 29, 1326-1336.

https://doi.org/10.1016/j.ijheatfluidflow.2008.04.009

Ramya Dodda, Srinivasa raju, R., Anandrao, J., Rashidi, M.M., 2016, "Boundary Layer Viscous Flow of Nanofluids and Heat Transfer over a Nonlinearly Isothermal Stretching Sheet in the Presence of Heat Generation/Absorption and Slip Boundary Conditions," Int.J.Nanosci.Nanotechnol.,12(4), 251-268.

Sandeep Naramgiri, Sulochana, C., 2015, "Dual Solutions for MHD Stagnation Point Flow of a Nano Fluid over Stretching Surface with Induced Magnetic Field," International Journal of Science and Engineering, 9(1), 1-8. http://dx.doi.org/10.12777/ijse.9.1.1-8
Sastry.D.R.V.S.R. 2015, "MHD Thermosolutal Marangoni Convection Boundary Layer Nano Fluid Flow Past a Flat Plate with Radition and Chemical Reaction," Indian Journal of science and technology, 8, 1-8. http://dx.doi.org/10.17485/ijst/2015/v8i13/55226

Shehzad. S.A., Hayat, T., Alsaedi, A., 2015, "Influence of Convective Heat and Mass Conditions in MHD Flow of Nanofluid," Bulletin of the Polish Academy of Sciences, 63(2), 465-474.

http://dx.doi.org/10.1515/bpasts-2015-0053

Turkyilmazoglu. M., 2016, "Natural Convective Flow of Nanofluids Past a Radiative and Impulsive Vertical Plate," J.Aerosp. Eng., 29(6), $1-8$. https://doi.org/10.1061/(ASCE)AS.1943-5525.0000643

Vafai, K., 2005, Handbook of porous media. $2^{\text {nd }}$ edn., Taylor Francis, New York.

http://doi.org/10.1201/9780415876384.

Venkataramanaiah. G., Sreedhar Babu, M., Lavanya, M., 2016, "Heat Generation / Absorption Effects on Magneto-Williamson Nano Fluid Flow with Heat and Mass Fluxes," International journal of engineering development and research, 4(1), 384-397. ISSN:2321-9939.

Vendabai. K., Sarojamma, G. , 2014, “Unsteady Convective Boundary Layer of a Nano Fluid over a Stretching Surface in the Presence of a Magnetic Field and Heat Generation," Int. J. of Emerging Trends in Eng. and Dev., 4(3), 214-230. ISSN: 2249-6149. 